\title{
Research Article \\ HERITABILITY ESTIMATES OF ADULT BODY WEIGHT AND EGG PRODUCTION TRAITS IN INDIGENOUS UTTARA CHICKENS
}

\author{
SINGH M.K. ${ }^{* 1}$, KUMAR S. ${ }^{2}$, SHARMA R.K. ${ }^{2}$, SINGH S.K. ${ }^{2}$, SINGH B. ${ }^{2}$ AND SINGH D.V. ${ }^{2}$ \\ 1Department of Poultry Science, Uttar Pradesh Pandit Deen Dayal Upadhyaya Pashu Chikitsa Vigyan Vishwavidyalaya Evam Go-Anusandhan Sansthan, Mathura, \\ 281001, Uttar Pradesh, India \\ 2Department of Livestock Production Management, Govind Ballabh Pant University of Agriculture and Technology, Pantnagar, 263 145, Uttarakhand, India \\ *Corresponding Author: Email- drmksingh_1@rediffmail.com
}

Received: February 10, 2018; Revised: March 24, 2018; Accepted: March 25, 2018; Published: March 30, 2018

\begin{abstract}
Data on female adult body weight and egg production measurements were analysed to obtain their heritability estimates. The mean values for body weight and egg production at various ages showed good performance of indigenous Uttara chicken. The heritability estimates observed for body weight decrease with increasing age of birds. The heritability values for various egg production traits at 40 and 58 weeks were low too high in magnitude. Changes in heritability estimates across different ages indicated expression of different genes at different ages of the Uttara fowl and the reduction of environmental effects as the flock is maintained under quite uniform environmental conditions.
\end{abstract}

Keywords- Adult body weight, Egg production, Heritability, Uttara chickens.

Citation: Singh M.K., et al., (2018) Heritability Estimates of Adult Body Weight and Egg Production Traits in Indigenous Uttara Chickens. International Journal of Genetics, ISSN: 0975- 2862 \& E-ISSN: 0975-9158, Volume 10, Issue 2, pp.-357-359. DOl: http://dx.doi.org/10.9735/0975-2862.10.2.357-359

Copyright: Copyright@2018 Singh M.K., et al., This is an open-access article distributed under the terms of the Creative Commons Attribution License, which permits unrestricted use, distribution and reproduction in any medium, provided the original author and source are credited.

Academic Editor / Reviewer: Dr Vijay Kumar

\section{Introduction}

A native chicken population from Uttarakhand, named as "Uttara fowl" is a distinctive bird with rich black plumage and feathered shank which has recently been identified [1]. It has medium egg production, medium growth rate, medium body size, medium-sized egg weight as well as moderate sexual maturity. It is found in high hills of Pithoragarh, Almora and Nainital districts and kept by mostly tribes in the interior parts of the of Uttarakhand and adjoining Nepal and Tibet border. This germplasm has a number of desirable characters such as hardiness, adaptability to the wide agro-climatic variability, disease tolerance, and rich flavor of meat and eggs. The Uttara chickens have resistance to diseases compared with other exotic breeds its natural habitat in free range [2]. Recently, there has been increasing interest in studying indigenous chicken breeds [2]. The genetic characterization of indigenous breeds is of paramount importance, not only for conservation purposes but also for the definition of breeding objectives and the development of breeding programmes. The optimum body weight is important for the proper expression of the economic traits. Birds start laying after attaining a certain level of body weight, which is necessary for the normal physical functioning. It is therefore essential that optimum body weight is achieved by the pullets during rearing and growing periods. Generally, selection of parents is done on the basis of part year egg production records due to its high and positive correlation with annual egg production. The production characteristics of modern laying hens vary, principally according to breed, environmental factors and the incidence of diseases. Egg production may be affected by feed, water, light, diseases, management and environmental factors. The objective of this study was to estimate heritabilities of adult female body weight and egg productions of Uttara chickens raised in the Uttarakhand, India.
The present study was carried on female Uttara fowls at the Instructional Poultry Farm (IPF), of Govind Ballabh Pant University of Agriculture and Technology, Pantnagar, U.S. Nagar. The place is located between $28^{\circ} 53^{\prime} 23^{\prime \prime}$ to $30^{\circ} 27^{\prime} 50^{\prime \prime} \mathrm{N}$ and $77^{\circ} 34^{\prime} 27^{\prime \prime}$ to $81^{\circ} 02^{\prime} 22^{\prime \prime} \mathrm{E}$ at $243.84 \mathrm{~m} \mathrm{MSL}$ (mean sea level) in the Tarai region of Uttarakhand State (India). The climate is humid sub-tropical. Winters are very severe and summers are hot and humid. Temperatures may rise to a maximum of $43^{\circ} \mathrm{C}$ in the summer and fall to a minimum of $2^{\circ} \mathrm{C}$ in the winter. Relative humidity ranges between 15 to $95 \%$ [3]. The pedigreed population under present study descended from 25 sires and 200 dams which were raised under uniform farm conditions has been presented in [Table-1]. Body weight was recorded on an electronic balance in morning before feeding starting from 24 to 40 weeks at 4 weeks intervals. Sex-wise genetic and phenotypic parameters of traits were estimated using the following statistical model after taking care of hatch effect in female adult body weight and production traits:

$$
Y_{i j k}=\mu+h_{i}+s_{j}+e_{i j k}
$$

$Y_{i j k}=$ observation on $k^{\text {th }}$ progeny of $j^{\text {th }}$ sire in $i^{\text {th }}$ hatch,

$\mu=$ population mean,

$h_{i}=$ fixed effect due to $i^{\text {th }}$ hatch $(i=1,2, . . H)$,

$s_{j}=$ random effects due to $j^{\text {th }}$ sire $(j=1,2, . . S)$,

$e_{i j k}=$ random error associated with each $k^{\text {th }}$ observation with mean 0 and variance $\sigma_{e}^{2}$

\section{Statistical Analysis}

The least squares mean of heritability estimates of traits under study were estimated from sire component of variances and covariances using MMLSML computer programme [4]. 
Table-1 Experimental population at different weeks of age for various traits under

\begin{tabular}{cccc}
\multicolumn{4}{c}{ study $^{*}$} \\
\hline Sire & Dam & Traits in week & Female (nos.) \\
& & $\mathrm{BW}_{24}$ & 470 \\
& & $\mathrm{BW}_{28}$ & 468 \\
25 & \multirow{4}{*}{200} & $\mathrm{BW}_{32}$ & 463 \\
& & $\mathrm{BW}_{36}$ & 460 \\
& & $\mathrm{BW}_{40}$ & 457 \\
& & WK $_{58}$ & 434 \\
\hline
\end{tabular}

* Some birds are culled during different ages.

\section{Results}

\section{Adult female body weight}

The least-squares means of $24,28,32,36$ and 40 weeks, of body weight of females have been presented in [Table-2] of Uttara fowl under present study which was computed to be $1394.62 \pm 3.76 \mathrm{~g}, 1547.86 \pm 19.47 \mathrm{~g}, 1563.44 \pm 20.43$ $\mathrm{g}, 1575.82 \pm 25.18 \mathrm{~g}$ and $1585.78 \pm 27.35 \mathrm{~g}$ respectively.

\begin{tabular}{|c|c|c|c|}
\hline SI. & Body weight (g) & Mean \pm S.E. & $h^{2} \pm S . E$. \\
\hline 1 & 24 weeks $\left(\mathrm{BW}_{24}\right)$ & $1394.62 \pm 3.76$ & $0.69 \pm 0.06$ \\
\hline 2 & 28 weeks $\left(B W_{28}\right)$ & $1547.86 \pm 19.47$ & $0.54 \pm 0.07$ \\
\hline 3 & 32 weeks $\left(\mathrm{BW}_{32}\right)$ & $1563.44 \pm 20.43$ & $0.46 \pm 0.02$ \\
\hline 4 & 36 weeks $\left(\mathrm{BW}_{36}\right)$ & $1575.82 \pm 25.18$ & $0.42 \pm 0.01$ \\
\hline 5 & 40 weeks $\left(B W_{40}\right)$ & $1585.78 \pm 27.35$ & $0.41 \pm 0.02$ \\
\hline & Production traits & - & $\cdot$ \\
\hline 6 & 40 weeks $\left(\mathrm{EN}_{40}\right)$ nos. & $74.79 \pm 0.53$ & $0.14 \pm 0.05$ \\
\hline 7 & 58 weeks $\left(\mathrm{EN}_{58}\right)$ nos. & $148.90 \pm 1.71$ & $0.24 \pm 0.02$ \\
\hline 8 & 40 weeks $\left(E W_{40}\right) g$ & $55.29 \pm 0.54$ & $0.47 \pm 0.13$ \\
\hline 9 & 58 weeks $\left(E_{58}\right) \mathrm{g}$ & $59.74 \pm 0.77$ & $0.44 \pm 0.22$ \\
\hline 10 & 40 weeks $\left(E M_{40}\right) g$ & $4134.83 \pm 42.86$ & $0.24 \pm 0.15$ \\
\hline 11 & 58 weeks $\left(E M_{58}\right) \mathrm{g}$ & $8895.21 \pm 70.88$ & $0.23 \pm 0.12$ \\
\hline
\end{tabular}

\section{Production traits}

The mean values of production traits viz. egg production, egg weight and egg mass up to 40 and 58 weeks of age were $74.79 \pm 0.53$ and $148.90 \pm 1.71$ eggs, $55.29 \pm 0.54$ and $59.74 \pm 0.77 \mathrm{~g}$ and $4134.83 \pm 42.86$ and $8895.21 \pm 70.88 \mathrm{~g}$ respectively.

\section{Heritability estimates of female adult body weight}

The heritability values for body weight at $24,28,32,36$ and 40 weeks were $0.69 \pm$ $0.06,0.54 \pm 0.07,0.46 \pm 0.02,0.54 \pm 0.07$ and $0.41 \pm 0.02$ respectively.

\section{Heritability estimates of production traits}

The heritability estimates of production traits viz. egg production, egg weight and egg mass up to 40 and 58 weeks of age were $0.14 \pm 0.05$ and $0.24 \pm 0.02,0.47 \pm$ 0.13 and $0.44 \pm 0.22$ and $0.24 \pm 0.15$ and $0.23 \pm 0.12$ respectively.

\section{Discussion}

\section{Adult female body weight}

The 24 weeks body weight in females was comparable with the reports of [5] in Aseel and [6] in Uttara fowl female (comb type). Aseel and Kadaknath observed lower 24 weeks body weight [5]. However, [6] in Uttara fowl females (crown type) observed higher 24 weeks body weights. The higher 24 weeks body weight reflects better feeding and management of the flock during its growing period. The differences in 24 weeks body weight observed in the present study from those reported in the literature could be due to genetic reasons and variation in feeding and management of the flocks. The 28 weeks body weight in females was comparable with local Ghanaian chicken males (genotype Forest) [7]. The local Ghanaian chicken (genotype SASSO T44) and local Ghanaian chicken males (genotype Savannah) observed higher 28 weeks body weights whereas lower body weights in local Ghanaian chicken females (genotype Forest and Savannah) [7]. These variations in body weight might be due to differences in genotypes and environmental conditions. The 32 weeks body weight was lower as observed in Kadaknath [8]. The 36 weeks body weight in females was comparable with White Leghorn [9]. The 40 weeks body weight in females was comparable with White
Leghorn [10]. However, [5] in Kadaknath and [11] in Aseel observed lower 40week body weight. The 40-weeks body weight was higher as observed in Aseel [5].

\section{Production traits}

\section{Egg production up to 40 -weeks of age}

The average egg production up to 40-weeks was similar to [6] in Uttara fowl (crown type) and [12] in PD1 $\times$ PD4. The higher egg production was obtained [10] and [12] PD1 $\times$ PD3 and PD1 $\times$ IWI. However, present average was higher than those reported $[5,13,14,6,12]$. The reason for fairly higher egg production was that the flock was an elite desi strain which was being maintained under regular selection programme for increased egg production for more than 10 years.

\section{Egg production up to 58-weeks of age}

Reports on this trait could not be found in the literature.

\section{Egg weight at 40-weeks of age}

The egg weight at 40-weeks of age was comparable with the findings of [10], Dahlem Red and Dahlem Red $\times$ Desi $[15,12]$ and higher than those reported [5, $14,15]$. The higher egg weight and uniformity for mean egg weight of flock under study was due to consistent monitoring and intense selection for optimum egg weight for more than 10 years.

\section{Egg weight at 58-weeks of age}

The egg weight at 58-weeks of age was comparable [12] at 56 and 60-weeks of age.

\section{Egg mass at 40-weeks of age}

The egg mass at 40-weeks of age was comparable with [16] for PL1 and PL2 but lower than those reported [17].

\section{Egg mass at 58-weeks of age}

There were no reports available in the literature on this trait. The results of the present study revealed that Uttara flock had reasonable level of productivity with fair egg size and egg mass.

\section{Heritability estimates of female adult body weight}

The higher estimates of heritability were reported at 24 weeks [18]. However, in heavy female Turkey population UK was reported lower heritability estimates at 21 weeks [19]. The 28 weeks estimates of heritability which was comparable with [18]. The 32 weeks estimates of heritability which was comparable with [20]. A lower estimate of heritability was observed in female chicken [21]. However, higher estimates of heritability were reported [18]. The 36 weeks estimates of heritability which was comparable with [9]. However, higher estimates of heritability were reported [18]. The 40 weeks estimates of heritability were comparable with [10] and [22] in IWI $\left(h^{2} s\right)$. Lower estimates of heritability were reported [23] in dwarf chicken ( $h 2 d)$ and $\left(h^{2} s+d\right)$, [24,25] in 'IWN' strain of WLH, and [22] in IWH (h2s), (h2d) and (h2s+d) of WLH and IWI (h2d) of WLH. However, higher estimates of heritability were reported [23] in Dwarf chicken (h2s), [18, 25] in 'IWP' strain of WLH and [22] IWI $\left(h^{2} s\right)$ and $\left(h^{2} s+d\right)$ of WLH. The heritability value for body weight at $24,28,32,36$ and 40 weeks were moderate to high in magnitude. These traits can be improved by individual selection. The differences in heritability estimates could be attributed to method of estimation, breed, environmental effects and sampling error due to small data or sample size. Environmental (high temperature and humidity) and poor manage menta conditions are known to increase the residual variance and decrease the heritability estimate.

\section{Heritability estimates of production traits Egg production}

The heritability estimates at 40 weeks egg production were similar with the findings of [10] in IWP strain of WLH (h2d), [23] in Dwarf chicken (h2D), [24,22] in IWH and IWI $\left(h^{2} s\right)$. However, lower estimates heritability was reported [24] in 
chicken ( $h^{2} s$ and $\left.h^{2} s+d\right)$, [22] in IWI ( $h^{2} d$ and $\left.h^{2} s+d\right)$ and [12] at 40 weeks interval. The higher estimates of heritability were reported [10] in IWN strain of WLH $\left(h^{2} d\right)$ and $\left(h^{2} s+d\right)$ and [25] at 40 weeks of egg production. However, [10] in IWP strain of WLH $\left(h^{2} s\right)$ and $\left(h^{2} s+d\right)$ were reported lower heritability at 40 weeks of egg production. The low value of heritability obtained for this trait indicates very low additive genetic variation could have resulted due to intense selection going on for the egg production for over 10 years in the flock under study. The heritability value of 58 weeks egg production suggested moderate additive genetic variation in phenotypic expression of this trait.

\section{Egg weight}

The heritability estimates at 40-weeks egg weight were similar with the findings of [10] in IWP strain of WLH $\left(\mathrm{h}^{2} \mathrm{~s}\right)$. The lower estimates heritability was observed [10, 12, 22, 23, 25]. However, [23] in Dwarf chicken $\left(h^{2} d\right)$ and [10] in IWP strain of WLH $\left(h^{2} d\right)$ and $\left(h^{2} s+d\right)$ were observed higher heritability estimates of 40 weeks of egg weight. The higher heritability of egg weight than egg number, a fitness trait, is expected and is in line with findings of other researchers [10,12, 18]. The egg weight trait can be improved by using individual selection.

\section{Egg mass}

The IWP strain of WLH was observed lower estimates heritability at 40 weeks egg mass [25]. However, in IWN strain of WLH were observed higher estimates of heritability [25].

\section{Conclusion}

The results indicated that the Uttara flock under study was an elite flock with better growth rate leading to higher egg production, comparatively higher egg weight and moderately higher egg mass. The heritability value for body weight at $24,28,32$, 36 and 40 weeks were moderate to high in magnitude. The heritability values for various egg production traits at 40 and 58 weeks were low to high in magnitude. The heritability estimates based on sire component of variance indicated that sufficient additive genetic variance was available for all traits for selection to act upon for improving these traits in the flock under study.

Application of research: Genetic research is now directed towards the investigation of the productive efficiency of farm animals and birds. The results indicated that the Uttara flock under study was an elite flock with better growth rate leading to higher egg production, comparatively higher egg weight and moderately higher egg mass. These research-outcomes may serve as base information to the breeders and academicians for chalking out breeding strategy.

Research Category: Poultry Genetics

\section{Abbreviations:}

WLH: White leghorn

MMLSML: Mixed Model Least Squares and Maximum likelihood

Acknowledgement / Funding: The authors also thankful to the Director, Experiment Station, Dean, College of Veterinary and Animal Sciences and Instructional Poultry Farms (I.P.F.), Nagla, G.B. Pant University of Agriculture and Technology, Pantnagar, 263 145, Uttarakhand for providing necessary facilities to conduct the experiment. Author thankful to contribution of Dr. R. P. Singh, Retired Professor \& Head Department of Animal Breeding, College of Animal Sciences, CCS Haryana Agricultural University, Hisar.

\section{${ }^{*}$ Research Principle Investigator: Dr M. K. Singh}

University: Uttar Pradesh Pandit Deen Dayal Upadhyaya Pashu Chikitsa Vigyan Vishwavidyalaya Evam Go-Anusandhan Sansthan, Mathura, 281001, Uttar Pradesh Research project name or number: PhD Thesis

\section{Author Contributions: All author equally contributed}

Author statement: All authors read, reviewed, agree and approved the final manuscript Conflict of Interest: None declared

Ethical Committee Approval: Research work was approved by Institutional Animal Ethics Committee (IAEC) of G.B. Pant University of Agriculture and Technology, Pantnagar, 263 145, Uttarakhand, India

\section{References}

[1] Kumar S., Kumar A., Singh B., Sharma, R.K., Singh D.V., Singh S.K. (2014) Ind. Vet. J., 91 (09), 107-108.

[2] Singh M.K., Kumar S., Sharma R.K., Singh S.K., Singh Brijesh and Singh D.V. (2017) Ind. J. of Anim. Res., 51(5), 948-951.

[3] Singh M.K., Singh S.K., Sharma R.K. Singh, B, Kumar, S, Joshi S.K., Kumar S., and Sathapathy S. (2015) Iran. J. of Vet. Res., 16(1), 78-82.

[4] Harvey W.R. (1990) Users Guide for LSMLMW, Mixed Model Least Squares and Maximum Likelihood Computer Program. PC-2 Version. Ohio State University, Columbus, USA.

[5] Haunshi S., Niranjan M., Shanmugam M, Padhi M.K., Reddy M.R., Sunitha R. Rajkumar U. and Panda A.K. (2011) Poult. Sci., 90, 314-320.

[6] Ansari V.K. (2015) Comparative study on production performance of comb and crown ecotypes of Uttara fowl. Thesis, M.V.Sc. G. B. Pant University of Agriculture and Technology.

[7] Osei-Amponsah R., Kayang B.B. and Naazie A. (2012) Trop. Anim. Health Prod., 44, 29-34.

[8] Thakur M.S., Parmar S.N.S. and Pillai, P.V.A. (2006) Livest. Res. Rural. Dev., 18, Article 18.

[9] Sharma Lata, Singh Harpal, Sharma R.K. and Singh C.V. (2003) Ind. J. Poult. Sci., 38(2), 145-148.

[10] Veeramani P., Churchil R.R. and Kutty K.N. (2012) Inter. J. Vet. Sci., 1(2), $45-48$.

[11] Kumar R., Kalra S. and Singh S. (2013) Ind. J. Anim. Res., 47(2), 132-136.

[12] Padhi M.K., Chatterjee R.N., Rajkumar U., Bhattacharya T.K. and Bhanja S.K. (2015) Ind. J. of Anim. Sci., 85 (8), 883-888.

[13] Chatterjee (2013) DPR Annual Report (2013-2014) Directorate of poultry research Rajendra Nagar, Hyderabad. PP 88

[14] Haunshi S., Padhi M.K., Niranjan M., Rajkumar U., Shanmugam M. and Chatterjee R.N. (2013) Indian J. Anim. Sci., 83(1), 59-62.

[15] Jha D.K., Prasad S., Patel N. and Baskar K. (2013) J. Agri. Tech., 9(6), 14051410.

[16] Singh P.K. Verma S.K., Sharma R.K. and Singh B. (2002) Ind. J. Poult. Sci., 37, 172-174.

[17] Tewari R. (2003). Genetic studies on economic traits of a commercial strain of White Leghom. Thesis, M.Sc. G. B. Pant University of Agriculture and Technology.

[18] Osei-Amponsah R., Kayang B.B. and Naazie A. (2013) Anim. Genet. Res., 53, 45-50.

[19] Kranis A., Hocking P.M., Hill W.G. and Woolliams J.A. (2006) Br. Poult. Sci., 47 , 685-693.

[20] Singh B. (1996) Estimation of genetic parameters and divergence analysis of economic traits in White Leghorn. Thesis, M.Sc. G. B. Pant University of Agriculture and Technology.

[21] Grasteau S.M., Beaumont C., Duval E.L.V., Poivey J.P. Rochambeau H.D. and Ricard F.H. (1999) Br. Poult. Sci., 40, 44-51.

[22] Mishra A.K., Kataria M.C., Bais R.K.S., Kumar Sanjeev, Narayan Raj and Sharma R.D. (2014) J. of Livest. Biod., 4(1-2), 30-33.

[23] Rajkumar U., Reddy B.L.N., Padhi M.K., Haunshi S., Niranjan M., Bhattacharya T.K. and Chatterjee R.N. (2011) Ind. J. of Anim. Poult., 46 (2), 143-147.

[24] Rajkumar U., Rajaravindra K.S., Haunshi S., Niranjan M., Bhattacharya T.K. and Chatterjee R.N. (2012) Ind. J. of Anim. Sci., 82(6), 615-619.

[25] Meshram A.Y., Joshi R.S., Savaliya F.P. and Singh A.P. (2014) Ind. J. Field Vet., 10(2), 67-70. 